
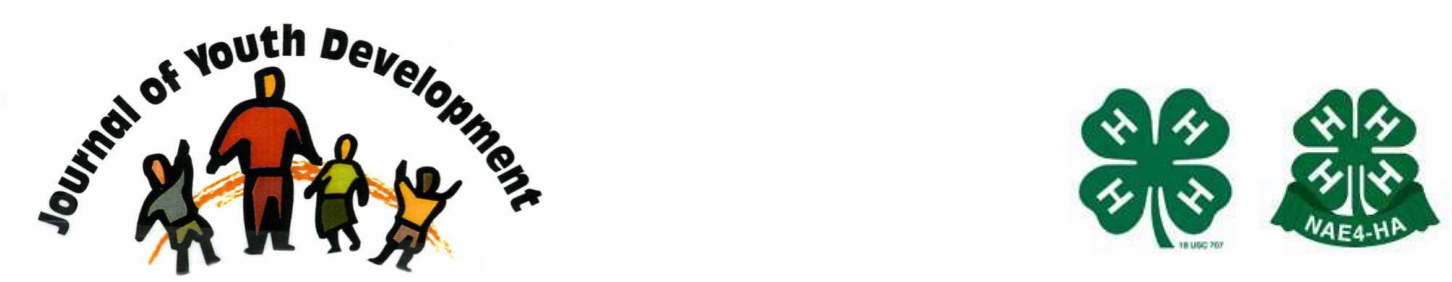

Bridging Research \& Practice

\title{
Engaging Adolescents as Community Organizers
}

\author{
Meredith Tetloff, MSW \\ VOX Teen Communications \\ Atlanta, GA \\ meredith@voxrox.org \\ Matt Griffith, MPH \\ vOX Teen Communications \\ Atlanta, GA
}




\title{
JOURNAL OF YOUTH DEVELOPMENT \\ bridging research and practice

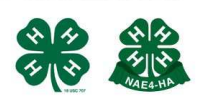

Volume 3, Number 2, Fall 2008

Article 080302PA001

\section{Engaging Adolescents as Community Organizers}

\author{
Meredith Tetloff and Matt Griffith \\ vOX Teen Communications
}

\begin{abstract}
VOX Teen Communications, a non-profit youth development organization in Atlanta, GA, positions adolescents as leaders in their community. Empowerment theory and a participatory approach are tools often utilized to achieve youth leadership. Teens participated in a community organizing project to create a "for-teens", "by-teens" resource guide Web site (www.teenresourceatl.org). This guide evaluates agencies, Web sites and hotlines on their "teen-friendliness" when providing services to youth in need. The empowerment-based program allowed the teens to take ownership of the project, resulting in a high level of commitment. Anticipated successes of the program include better access to help for teens in need; positioning teens as both users of the guide and leaders of the project; increased confidence and skill-level of the teen participants; and better informed service providers in the community.
\end{abstract}

\section{Engaging Adolescents as Community Organizers}

Youth development program directors face many challenges in designing successful programs, not the least of which is the active and continued participation of youth in the programs. Teenagers are exposed to a multitude of competing activities which they can prioritize over development programs, such as academics, sports, friends, family, television, radio, drugs, alcohol and video games. By shifting the power dynamic between youth and their reality to one in which they have more control over the decisions that affect their reality, empowerment has been suggested as an appropriate and effective approach to youth development (Fusoni, 2005; Wallerstein, 1994). A participatory approach to developing youth programs has also been suggested as a way to improve both research (Minkler, 2005; Wing, 1998) and health promotion programs (Minkler, 2005).

Empowerment theory purports that dialogue leads to consciousness raising (Freire, 1970). Programs based in empowerment theory can lead to individual enlightenment and increased awareness of the right to access existing resources and the rights and responsibilities of creating useful resources and reducing detrimental resources, such as social and structural 
institutions that promote risky behavior (Breton, 1994). For example, participants of an empowerment-based photovoice project showed increased self-competence, emergent critical awareness of their environment, and cultivation of resources for social and political action (Foster-Fishman, 2005).

A participatory approach to program development seeks the expert knowledge of the affected population in decision-making. Equitable partnerships are formed early in the issue identification stage and remain through the evaluation stage (Southeast Community Research Center, 2006). Participatory approaches hold that program directors bring expert knowledge of program development to the table and that youth bring expert knowledge about their concerns (Wallerstein, 1994).

Empowerment theory and a participatory approach often work in union. One possibility is that a participatory approach results in empowered individuals who have realized their self-worth. A second possibility is that an empowerment approach increases skills and self-confidence participants need to be active leaders. Programs representing either of these possibilities subscribe to an important principle of both approaches, Paulo Freire's praxis. Praxis is defined by Freire as "reflection and action upon the world in order to transform it" (Freire, 1970, p. 51). Reflection and action should be iterative throughout an effective program.

This article presents a case example of a successful adolescent development program aimed at informing youth about important health issues. The example displays the effective ways in which participatory and empowerment methods are used iteratively to develop a teen resource guide in Atlanta, GA.

\section{Case Example}

VOX Teen Communications (formerly Youth Communication: Metro Atlanta) is an Atlanta-based youth development organization founded in 1993. Teens come to VOX to create peer-to-peer information sources (a newspaper, Web site and other publications), full of real-life experiences and resources for connection to their audience of 80,000 peers. In this process, they reframe their own perceptions, learn more about themselves and their roles in the community, and educate their readers on important issues and resources for help and self-improvement.

In 2002, a group of teen participants at VOX Teen Communications indicated that there was a lack of information about resources available for adolescent self-help, specifically on sensitive topics such as sexual behavior and drug use. They created and implemented a needs assessment among more than 120 of their peers to determine if a need for self-help resource information existed and current methods teens use to access those resources. The assessment showed that $45 \%$ of youth surveyed in Atlanta did not have a way to get help for their personal problems, and of the $55 \%$ who did, their resources may not have been reliable or objective (Study organized by VOX in 2002-03).

As a result of the needs assessment, VOX's teen participants proposed creating a teen resource guide using their skills as writers and researchers. The guide would include basic information about issues affecting adolescents, derived from the needs assessment conducted among peers. The teens also decided to include descriptions of agencies, hotlines and Web sites that provide assistance related to selected issues. Unique to this guide is a teen-friendliness evaluation of each of the resources provided. The teen planners decided that examples of teen-friendliness include service hours in relation to school hours, minimal fees for services, and staff sensitivity to teen needs. 
The project was temporarily postponed as the original teen leaders graduated and left the area. In the fall of 2005, a new group of teen participants requested to be involved in a community organizing project. A trained adult volunteer organizer was contacted to assist with development of the project. In the first meeting, facilitated by the volunteer, teens developed visual definitions of community organizing, i.e., drawings. The teens' definitions were compared to definitions developed by academics (Minkler \&Wallerstein, 1999; Walter, 1999) and the internet and analyzed for differences and similarities. Next, teens enumerated steps they believed to be important for community organizing. These were compared to steps developed by the volunteer facilitator. These activities were used to achieve the objectives of the first meeting: to show the participants that they are capable of defining and owning their own community organizing project, thus creating ownership of the project, and to critically reflect on the nature of community organizing as a strategy for developing the resource guide

The next three workshops focused on goal setting, and were conducted through interactive methods based in adult-education principles, such as activities that emotionally connected participants to the subject matter and activities that are explicitly relevant to the identified issues. For an overview of adult learning principles, see "Principles of Adult Education" (http://honolulu.hawaii.edu/intranet/committees/FacDevCom/guidebk/teachtip/adults-2.htm).

Teen-identified objectives for the project included:

a) to create a list of community concerns;

b) to narrow the list based on teen-identified criteria, such as relevance to peers and feasibility of project completion, and;

c) to prioritize a primary concern.

The 12 teens participants prioritized a lack of reliable information on self-help resources for Atlanta teens as their chief concern. This issue led to the development of the project goal: "to provide reliable information for area teens on prioritized teen concerns." Subsequent project development occurred as follows:

- After initial workshops, the teens identified a resource guide as a potentially effective way of achieving the project goal.

- The teens then made a decision through consensus to endorse the resource guide as the strategy for achieving their goal.

- After developing the project's goals and objectives, teens reflected on their definitions of community organizing and decided to include a long-term goal: to use information from the resource guide to inform service providers about how to improve services provided to adolescent clients.

Thus, teen-identified goals and objectives fit with some goals of empowerment theory: creating useful resources and eliminating deficient resources.

- Next, participants created a timeline of implementation, which included continual reflection (evaluation).

- $\quad$ Teens then brainstormed ideas for the physical appearance and method of dissemination for the resource guide, determining that an internet-based guide was ideal because it would be accessible to most teens and would be easy to update. 
One of the identified project concerns included reaching peers who do not have access to the internet, such as homeless teenagers. The proposed solution: to educate their peers through a marketing campaign that would include suggestions of locations with free Internet access, such as the public library.

To keep with empowerment theory and participatory approaches, it was necessary to reflect on the process at this point and before further implementation occurred. A Freireian dialogue session was constructed with the teens to reflect on the development process and context. The use of a trigger or "code" is suggested by Freire to reflect the reality of participants back to them and thus prompt dialogue (1970). In this case, adult facilitators developed a poster that included teenage health statistics surrounded by photos of teenagers' faces. A directed discussion using the SHOWED method, as described in Wallerstein (1994), was facilitated by a trained adult volunteer facilitator in which teens reflected on the underlying social issues of their project. The session was a great success, with teenagers identifying a host of social, historical, political, generational, and cultural reasons for the lack of reliable information for teens. Content from the dialogue was then recommended by participants as important aspects to include in the development of the resource guide.

Next, teen and adult staff and volunteer personnel decided that collaborations would be necessary to facilitate leadership development and gain access to resources that would assist project implementation. Thus, partnerships were formed with local service organizations that have done similar work, including the United Way of Metropolitan Atlanta and the Georgia Campaign for Adolescent Pregnancy Prevention (G-CAPP). Both of these organizations have existing databases that were created by and for adults. The teens obtained this information from the existing resources and critically examined the content for teen user-friendliness. Information from these databases provided a useful method in identifying a vast number of resources potentially available to Atlanta teenagers.

After obtaining information from the databases, teens evaluated many of the resources listed on their teen-friendliness. Resources were evaluated based on:

1. Times the resources are available. For example, an agency only open during school hours would not be teen-friendly.

2. Public transportation accessibility. The teen creators of the resource guide wanted to provide their peers with resources that are accessible without owning a car or depending on someone else for transportation.

3. Confidentially. Several of the issues the guide provides help on are sensitive, such as pregnancy or drug addiction. Therefore, the guide's creators prioritized the need for teens seeking help to feel confident that they could do so without parental permission or the fear of others finding out about their problem.

4. No or low fees. The guide's creators did not want cost to prevent their peers from getting help and therefore believe that no or low payments are teen-friendly.

Additional partnerships were formed with adults who work in various professions relevant to the resource guide development. These adults serve as volunteers to assist with training and supporting the teens in community organizing, project management, investigative journalism, marketing and web site design.

In addition to continued praxis (i.e., reflection and action), teens have been involved in evaluating the project. Participants identified desired outcomes and suggested methods of 
measuring each. For example, to measure increased access to resources for adolescents, the teen program managers decided to evaluate numbers of hits to the Web site and a Web-based survey about whether the guide and the information teen users received from it was helpful.

While the project described here continues to develop, launch of the web-based teen resource guide occurred in January 2007 It can be viewed at www.teenresourceatl.org.

\section{Conclusion}

This program illustrates a successful way to use praxis, the iterative processes of action and reflection, through a combined empowerment theory-based and participatory approach to nonprofit youth program development. The participatory approach used in the development of the teen resource guide involved equitable partnerships in every step of this project where feasible. An empowerment-based approach enabled teens to develop confidence and serve as project leaders with adult support, resulting in increased participation, development of positive resources and reduction of detrimental resources. Teens identified issues, objectives, goals, and implementation strategies, making their decisions by consensus. By using these approaches, several benefits were observed.

- First, the teens became users of their own intervention, the resources guide.

- Second, because the guide is based in the teens' experiences, its format and content will more likely resonate with other area teens.

- Third, an overall sense of empowerment was achieved as teens created new knowledge surrounding the issue of reliable and relevant information for teen issues.

Teenage participants demonstrated individual empowerment through the acquisition of new skills including research, web design, marketing, community organizing, writing, editing, and professional communication among collaborating partners.

This example recommends that youth development program directors adopt a participatory and empowerment-based approach to program development and implementation. Specifically, we recommend:

1. transferring power to the teen participants so that power is shared more equitably;

2. including teens in project development at the earliest stages possible;

3. providing frequent opportunities for praxis (reflection and action);

4. supporting youth with training from adult experts, then providing youth opportunities for hands-on application of their new skills;

5. making decisions through consensus in order to gain group ownership; and

6. collaborating with local available resources 


\section{References}

Breton, M. (1994). On the meaning of empowerment and empowerment-oriented social work practice. Social Work with Groups, 173). 23-37.

Foster-Fishman, P., Nowell, B., Deacon, Z., Nievar M.A., \& McCann, P. (2005). Using methods that matter: the impact of reflection, dialogue, and voice. American Journal of Community Psychology 36(3-4):275-291.

Freire, P. (1970). Pedagogy of the Oppressed. New York: Seabury Press.

Fusoni, M. (2005). Teen empowerment: youth, police, and neighbors in partnership. New Directions for Youth Development Summer (106):61-71, 5-6.

Minkler, M. (2005). Community-based research partnerships: challenges and opportunities. Journal of Urban Health 82(2 Suppl 2):ii3-12.

Minkler, M., \& Wallerstein, N. (1999). Improving health through community organization and community building: A health education perspective. In M. Minkler (Ed.), Community building and community organizing for health (30-52). New Brunswick, NJ: Rutgers University Press.

Southeast Community Research Center. (2006). Community-based participatory research. Retrieved June 7, 2006 from http://www.cbpr.org.

Wallerstein, N. (1994). Empowerment education applied to youth. In Matiella (Ed.). Multicultural challenge in health education (153-176). Santa Cruz, CA: ETR Associates.

Walter, C. (1999). Community building practice: A conceptual framework. In M. Minkler (Ed.), Community building and community organizing for health (68-86). New Brunswick, N]: Rutgers University Press.

Wing, S. (1998). Whose epidemiology? Whose health? International Journal of Health Service 28(2): 241-52.

(C) Copyright of Journal of Youth Development Bridging Research and Practice. Content may not be copied or emailed to multiple sites or posted to a listserv without copyright holder's express written permission. Contact Editor at: patricia.dawson@oregonstate.edu for details. However, users may print, download or email articles for individual use.

ISSN 2325-4009 (Print); ISSN 2325-4017 (Online) 